OPEN ACCESS

Edited by:

Douglas F. Kauffman,

Medical University of the

Americas-Nevis, United States

Reviewed by:

Meryem Yilmaz Soylu,

University of Nebraska-Lincoln,

United States

Sherri Horner,

Bowling Green State University,

United States

*Correspondence:

Marc D. Hause

marc@risk-eraser.com

Specialty section

This article was submitted to

Educational Psychology,

a section of the journal

Frontiers in Education

Received: 05 November 2018

Accepted: 07 March 2019

Published: 28 March 2019

Citation:

Hauser MD (2019) Patience! How to

Assess and Strengthen Self-Control.

Front. Educ. 4:25.

doi: 10.3389/feduc.2019.00025

\section{Patience! How to Assess and Strengthen Self-Control}

\author{
Marc D. Hauser* \\ Risk-Eraser, West Falmouth, MA, United States
}

Children often show signs of dysregulation, impulsivity, and risk-taking-behaviors that interfere with learning and growth. Commonly implicated in such interfering behaviors are problems of self-control. Several decades of research in the mind and brain sciences inform understanding of self-control, both as a trait and state. This research has significant implications for educators, providing strategies for assessing and strengthening self-control. This paper reviews the relevant theoretical concepts and practical applications. Part one discusses current thinking about the nature of self-control, focusing on the paired distinctions between (i) trait and state, as well as (ii) volitional and impulsive processes. Part two reviews a family of methods designed to assess different aspects of self-control. Part three focuses on ways to strength self-control, including simple strategies that help create habits and reduce conflict with competing temptations.

Keywords: self-control, assessment, strengthening, trait, state, volitional, impulsiveness

Throughout development, children are commonly challenged by emotional dysregulation, impulsivity, and risk-taking-behavioral indicators of poor self-control. These behaviors impede personal and peer learning, whether the content is social-emotional or academic. The good news is that the mind and brain sciences have developed simple, effective strategies to assess, and strengthen self-control that are ideal for helping all children, whether in general or special education. This paper reviews these strategies. Part 1 clarifies some of the core conceptual issues surrounding the capacity for self-control, focusing especially on distinctions that make a difference to understanding and enhancing a child's growth. Parts 2 and 3 discuss, respectively, methods for assessing and strengthening self-control.

\section{PART 1. CONCEPTUAL ISSUES}

The traditions of cognitive science and education tend to split when it comes to terminology, with the former more consistently using self-control while the latter uses self-regulated learning (Nigg, 2016). Though there is overlap among these terms, the capacities they pick out are distinctive, including the methodologies for assessing and enhancing them (Duckworth et al., 2014; Milyavskaya et al., 2019). The focus in this paper is exclusively on self-control because it is less familiar to many educators, but clearly enhances and complements the work on self-regulated learning (Wery and Nietfeld, 2010; Korinek and deFur, 2016).

Self-control entails the ability to regulate emotions, attention, and behavior when conflict emerges between two competing options, one available immediately, and one delayed into the future (Baumeister et al., 2007; Duckworth et al., 2019). Self-regulated learning, in contrast, focuses on the strategies used to monitor progress, obtain feedback, and garner support in the service of 
attaining social-emotional and academic goals (Cole et al., 2018). The key difference, then, is that self-control-but not selfregulated learning-always involves a conflict experienced and managed by the individual between short- and long-term goals.

In considering the capacity for self-control, it is important to make two further distinctions. The first is between trait and state self-control. Trait self-control (de Ridder et al., 2011) refers to aspects of our underlying biology that are typically consistent and long lasting over a life time. Studies of trait self-control reveal the predictive power of early assessments for later life outcomes including health, wealth, and education (Casey et al., 2011; Moffitt et al., 2011). In addition, studies reveal that individuals with high trait self-control experience conflict as less disruptive in part because they develop stronger habits and more effortlessly downregulate their emotions than those with low self-control (Gillebaart and de Ridder, 2015); such benefits arise in a variety of contexts including the consumption of healthy snacks, study habits, homework completion, and persistence during the first year of college (Galla and Duckworth, 2015). Though trait selfcontrol is rooted in our biology, it is not immutable (Foulkes and Blakemore, 2018; Pandey et al., 2018) - a point of great relevance to educators considering opportunities to strengthen this capacity (Part 3).

State self-control refers to temporary and often changing aspects of self-control that can arise within a day or shorter periods of time due to motivation, experience, and environmental circumstances. Research on state self-control suggests that it is a limited resource, one that can be depleted through use, with negative consequences for self and society (Baumeister et al., 2018). For example, individuals with low state self-control are more likely to engage in unethical, rude and inappropriate behavior (DeBono et al., 2010; Gailliot, 2012), and court judges are more likely to turn down a prisoner's request for parole as their state self-control diminishes within a day (Danziger et al., 2011); strikingly, the decline in judges' willingness to grant parole reboots following periods of food consumption, suggesting that certain kinds of breaks replenish the resources supporting state self-control.

The second distinction is between volitional as opposed to impulsive processes (Duckworth and Steinberg, 2015). Volitional processes support self-control and include attention, monitoring, planning, persevering, and inhibition. Most of the processes underlying the volitional side of self-control fall under the purview of executive functioning (Diamond, 2013). Impulsive processes, in contrast, derail self-control and include heightened sensitivity to rewards, risk-taking, a presentoriented/future devalued perspective, and specific addictions or cravings.

The volitional-impulsive distinction is particularly significant for school-aged children as the underlying processes change during development, at different rates, and on a time-course that appears universal for typically developing populations. For example, in significant cross-cultural research by Steinberg et al. (2017), results show that sensation-seeking peaks at around 19 years whereas self-control peaks and remains stable between 23 and 26 years (Figure 1). Significantly, then, impulsive processes such as sensation-seeking reach a heightened state before self-control has fully matured (Foulkes and Blakemore, 2016). These different maturational trajectories help explain why adolescence is associated with the appearance of reckless and personally harmful decisions and actions-indicative of a failing self-control system-despite a steady increase in volitional capacity. The take-home message is that educators must assess both the volitional and impulsive processes underlying behavior as either or both may be responsible for derailing the opportunity to learn and make good decisions.

The trait-state and volitional-impulsive distinctions have direct relevance to teachers, including not only how they help children grow but how they manage their own effectiveness. Due to individual differences that are expressed early in life, some children-especially those with emotional disturbances-will arrive in the classroom with low trait self-control, diminished state self-control, high reward sensitivity, and weak executive functioning that underlies volitional self-control. For such children, the challenges are numerous, with attention derailed and the ability to persist compromised. For both student and teacher, it is important to recognize and adjust the flow of each day as use of self-control will result in lowered state self-control. Lowered state self-control is associated with lowered attention and ability to plan, as well as more reactive, impulsive aggression (Osgood and Muraven, 2015).

The conceptual distinctions discussed here are essential to the selection and implementation of strategies to assess and strengthen self-control. I turn next to these strategies, starting first with assessments.

\section{PART 2. ASSESSING SELF-CONTROL}

Emotional outbursts, aggression, frustration, and impatience are often associated with early childhood, and heightened in cases of students with emotional disturbances. This suite of behaviors often reflects poor self-control (Kauffman and Landrum, 2013). But these behaviors can be caused by other cognitive and sensory problems. For these reasons, and others, it is important to assess self-control, selecting tools that will provide diagnostics for the different dimensions associated with this capacity.

There are many types of self-control assessment, designed to address different aspects of this capacity, often with different methodologies (for reviews, see Duckworth and Kern, 2011; Duckworth and Yeager, 2015). These differences should be considered in light of both the target population and the ultimate motivation underlying assessment. In particular, and as further developed below, some assessments require a particular level of reading competence (e.g., questionnaires), specific motor skills (e.g., computer-based tasks), as well as other cognitive functions (e.g., sustained attention, motivation) linked to comprehension of rules, and decisions. Other assessments require particular resources, including access to computers or rooms where students can be evaluated alone, as well as staff who can reliably assess naturally occurring social behaviors. As such, choosing the appropriate assessment tool will depend on the target population's age and cognitive limitations, as well as the availability of particular resources. Lastly, and as insightfully 


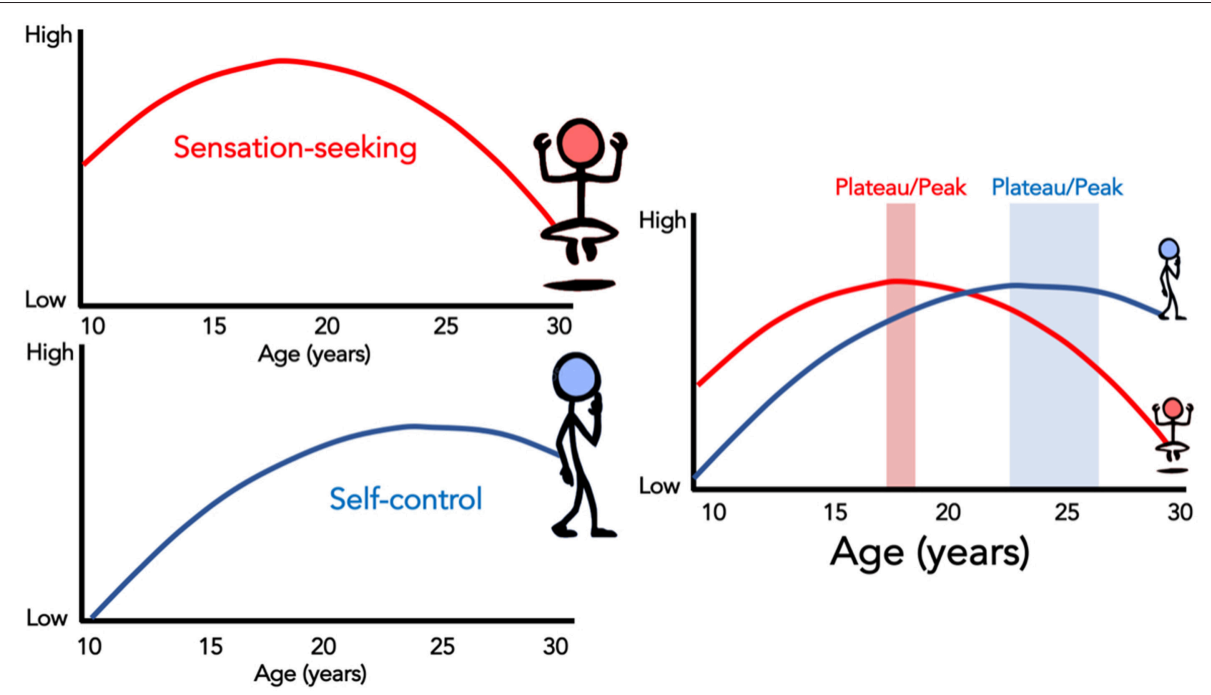

FIGURE 1 | Changes in sensation-seeking (left, top) and self-control (left, bottom) as a function of age (adapted from Steinberg et al., 2017). Both sensation-seeking and self-control were derived from a composite measure including surveys and performance assessments. The chart on the right superimposes the developmental trajectories of sensation-seeking and self-control and shows (light red, light blue) differences in the timing of their respective peaks and plateaus.

noted by Duckworth and Yeager (2015), assessments of selfcontrol, along with other social-emotional competences, are not yet at the stage where a single method precisely and unambiguously reveals an individual's or population's selfcontrol competency. Rather, a combination of assessments is required.

Table 1 provides an overview of three different types of self-control assessment, roughly organized in terms of how the evidence is acquired: (1) Questionnaires, (2) Computeror Person-based games/activities, and (3) Observations of naturally occurring behaviors. Linked to each assessment type are some specific examples along with a list of advantages and limitations.

All three assessment types allow teachers to evaluate both volitional and impulsive processes, though with different levels of precision. To illustrate, consider the classic conflict between an immediate as opposed to a delayed outcome. This conflict is known as delayed gratification or temporal discounting, brought to the attention of many educators by the famous "marshmallow test" (Mischel, 2014). There are many ways of assessing delayed gratification, including the use of all three types of approaches. For example, individuals can be given a hypothetical (Questionnaire) or actual (Person-based) choice between a relatively small but immediate outcome (one piece of candy or $\$ 1$ ) as opposed to larger but delayed outcome (10 pieces of candy or $\$ 10$ in 5 days); this ability to vary the outcomes is important in considering the age group assessed, as young children are much more likely to be motivated by candy, whereas older children, especially high school students, are more likely to be motivated by money or gift cards. In addition, teachers may use more natural Observations, watching as a student works on a math worksheet, assessing how often he is distracted by more immediately gratifying experiences such as talking with a peer or playing on an iPad.
In choosing a particular assessment tool, teachers must consider (1) what aspects of self-control are to be assessed, (2) whether the requirements for implementation can be satisfied, including the availability of resources, and (3) the limitations of the tool(s) selected. Some questionnaires (e.g., Grit scale) and online games/activities (e.g., Stroop task) focus on a relatively narrow aspect of self-control, whereas others (e.g., DESSA, observations of coping skills) cover a broader range. Questionnaires have a low financial and time cost burden, and can be disseminated by paper or online. However, questionnaires have limitations. In particular, students may not understand the wording of the questions or the meaning of the response scale, may provide desirable answers as opposed to honest ones, and are likely to be heavily influenced by the mood of the day as opposed to considering the broader focus of the question (e.g., When asked "Do you think before you answer?" this is an "in general" question as opposed to a "today" question). In cases where questionnaires are given repeatedly, say at the start and end of the year, this has the potential to reveal change, but can be confounded if students recall earlier answers and strive for consistency as opposed to accuracy.

Games and activities, whether online or in person, have the advantage that they are often more engaging than questionnaires, and often are presented in a highly controlled context, which is not the case for observations of naturally occurring behaviors. The engagement obtained by games is perhaps especially important for older students, and in particular, for students in special education who are likely to have taken many surveys and written assessments. Many games and activities are now available online, and with the advent of simple, freely available programming languages (e.g., PEBL: http://pebl.sourceforge. net/), it is possible to create one's own. The advantage of a highly controlled context and format for presenting assessment material is also a potential limitation, as performance in the game or 
TABLE 1 | Different types of assessments for self-control.

\begin{tabular}{|c|c|c|c|}
\hline Assessment type & Examples & Advantages & Limitations \\
\hline Questionnaires & $\begin{array}{l}\text { - Barratt impulsiveness scale } \\
\text { - Grit scale } \\
\text { - Brief self-control survey } \\
\text { - Devereux student strength assessment }\end{array}$ & $\begin{array}{l}\text { - Low cost in terms of resources and time } \\
\text { - Easy to administer } \\
\text { - Can compare student, teacher, and } \\
\text { parent responses } \\
\text { - Highly validated for different populations } \\
\text { and age groups } \\
\text { - Can assess a broad range of } \\
\text { components or processes of self-control }\end{array}$ & $\begin{array}{l}\text { - Not understanding terms or scale } \\
\text { - Biased responses to appeal to what is } \\
\text { - } \text { cunted or desirable } \\
\text { can bias responses } \\
\text { - If repeated (pre vs. post), responses } \\
\text { may reflect attempt to be consistent }\end{array}$ \\
\hline $\begin{array}{l}\text { Computer-/person-based } \\
\text { activities/games }\end{array}$ & $\begin{array}{l}\text { - } \text { Balloon analog risk task } \\
\text { - Delayed gratification, temporal } \\
\text { discounting tasks } \\
\text { - Stroop and Set-switching tasks } \\
\text { - Commercial, online games (e.g., } \\
\text { Go/NoGo, Flanker variants) }\end{array}$ & $\begin{array}{l}\text { - } \text { Numerous quantitative measures (e.g., } \\
\text { - Lecuracy, reaction times) } \\
\text { - } \text { measurement goal } \\
\text { - Less transparent as an assessment } \\
\text { - Controlled assessment environment } \\
\text { - Engaging }\end{array}$ & $\begin{array}{l}\text { - Extraneous factors or skills can influence } \\
\text { response (e.g., motor skills, video } \\
\text { game players) } \\
\text { - Artificiality of activity/game may not } \\
\text { generalize to real world } \\
\text { - If repeated, experience in game play } \\
\text { may impact assessment as opposed to } \\
\text { change in self-control } \\
\text { - Near, but not far generalization }\end{array}$ \\
\hline $\begin{array}{l}\text { Observations of naturally } \\
\text { occurring behavior }\end{array}$ & $\begin{array}{l}\text { - Staying on task } \\
\text { - Use of coping skills when frustrated } \\
\text { - Absence of aggression, rude comments } \\
\text { - Zones of regulation }\end{array}$ & $\begin{array}{l}\text { - Naturally and frequently occurring } \\
\text { contexts } \\
\text { - Relevance to social-emotional skill } \\
\text { development } \\
\text { - In class baselines can be collected and } \\
\text { used to set up and assess growth } \\
\text { targets } \\
\text { - Opportunity to design interventions to } \\
\text { specifically target measured behaviors } \\
\text { - Customized to specific student, thus } \\
\text { often directly relevant to individualized } \\
\text { education program }\end{array}$ & $\begin{array}{l}\text { - Difficult to control environmental triggers } \\
\text { - May not observe antecedents } \\
\text { - May not assess all relevant factors } \\
\text { associated with behavior } \\
\text { - Challenges of operationalizing behavior } \\
\text { and obtaining high } \\
\text { inter-observer reliability }\end{array}$ \\
\hline
\end{tabular}

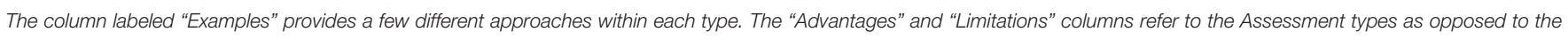

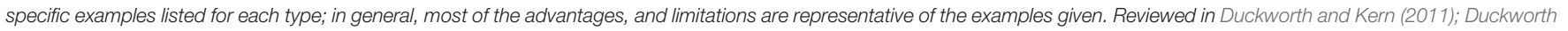
and Yeager (2015).

activity may not generalize to performance in less controlled, more natural settings.

For many educators, perhaps especially those working in small, therapeutically oriented classrooms, assessments are carried out with observations and recordings of naturally occurring behaviors, some linked to the student's Individual Education Program or IEP. As such, there is a mandate to provide evidence of growth on the use of volitional processes such as coping skills and thinking-before-acting, as well as decreases in impulsive processes that can trigger aggression, tantrums, and bolting. The advantage of such observations, when coupled to reliable sampling methods, is that they capture how children react to real world challenges to the capacity for self-control. For example, if staff operationally define the kinds of behaviors that present when a child is dysregulated (e.g., tantrums and flopping to the ground for young children, profanities, and aggression with older children), and record the frequency and duration of such behaviors as well as their antecedents, it is possible to assess changes in self-control during the day, and potentially some of the causes of variation. A disadvantage of natural observations is that little is controlled, including the composition of students and staff, time of day, activities, and opportunities.

In summary, there are advantages and limitations to all three types of assessment. Ideally, a combination of assessments should be used. Critically, the assessments are necessary prior to and following interventions designed to strengthen self-control-our next topic.

\section{PART 3. STRENGTHENING SELF-CONTROL}

Before one attempts to strengthen a capacity or skill, it is necessary to understand how it works, whether there is reason to believe it can be changed, and if so, when and how (Berkman, 2016). With respect to the functioning of selfcontrol, Part 1 emphasized two relevant distinctions and the processes associated with them: (1) trait vs. state and (2) volitional vs. impulsive. Thus, the issue of strengthening selfcontrol should, minimally, explore these underlying processes. Part 1 also noted evidence of change in trait self-control, including both volitional and impulsive processes, though with each on a different maturational time course (Figure 1). Lastly, there is the question of whether and how self-control as a state can be changed, and in particular, whether the daily decrease in this capacity can be arrested or even reversed. As previously noted, judges adjudicating over parole cases reversed the downward slope of rejections by eating, suggesting 
that the loss of resources for self-control can be rebooted by certain activities.

Table 2 provides a broad overview of some of the approaches to self-control strengthening (Berkman et al., 2012; Pandey et al., 2018). In parallel with the overview of assessments, the work on strengthening is organized according to three types: (1) Practicing self-control, (2) Goal attainment, and (3) Mental transformations. All three have the advantage that they are low in resource costs and time, simple to implement, and readily understood by children of different ages. All three types are limited, however, by lack of understanding concerning longterm, sustained benefits, as well as the required frequency of exposure to observe significant effects.

Practicing self-control grew out of the research on self-control as a state, one that is limited and can be depleted through use (Baumeister et al., 2018). Studies show that if individuals exert self-control, say by squeezing a handgrip for as long as they can, they subsequently have greater difficulty persisting on a difficult word problem. Follow-up research shows that if you repeatedly exert effort on a task or activity that requires volitional self-control, you soon (within 2-8 weeks) gain greater capacity for self-control. Specifically, self-control training with handgrip squeezing, non-dominant hand use, refraining from swearing or eating sweets, or maintaining a straight posture, provided benefits in self-control capacity far outside the domain of training. For example, individuals who twice-daily used their non-dominant hand for 2 weeks showed reduction in aggression toward others; individuals who avoided sweets or practiced a handgrip for 2 weeks showed a reduction in smoking; individuals who practiced a handgrip or suppressed swearing for 2 weeks subsequently solved more anagrams (i.e., gave up less easily). As noted, these strengthening exercises, along with game-like versions for younger children (Tominey and McClelland, 2011), are cost and time effective, and simple for teachers to weave into the ongoing flow of a day or class (e.g., use non-dominant for writing assignments). For example, for children up to middle school age, playing a negation version of Head-Shoulders-KneesToes directly taps both motor and cognitive self-control as the observing child has to do the opposite of what the demonstratinglead teacher does: Teacher says "Touch your toes" while touching her toes, but children have to touch their head. For older children, it is possible to convert the fast pace game of dodge ball-where individuals on teams use a ball to tag out individuals on the opposing team-into a self-control task linked to the Stroop task. Individuals on each team where, say, yellow and green shirts, and play with both yellow and green balls. When the teacher calls out "Match," yellow balls can only be used to tag yellowshirted players from the other team, green balls to tag out greenshirted players. When the teacher calls out "Mismatch" the rule switches: yellow balls tag out green-shirted players and green balls tag out yellow-shirted players. Like the Stroop task, a prior association must be admitted; in addition, by switching between Match and Mismatch, individuals must alternate between rules, thereby further engaging the self-control system.

The goal attainment approach is actually a suite of methods designed to bypass volitional processes, focusing instead on automatizing habits or routines. As several authors suggest
(Duckworth et al., 2016), those high in trait self-control actually appear to use less self-control in daily life, using habits to avoid conflict from derailing temptations, including those that arise in a school setting (Galla and Duckworth, 2015). One of the most effective and supported approaches involves reframing goals as IF-THEN statements or implementation intentions, where the IF specifies the situational trigger or context and THEN specifies the behavior or action that follows (Gollwitzer, 1999; Oettingen and Gollwitzer, 2015). One of the reasons implementation intentions are effective is that they create automatic, habitual responses. When individuals are cued by the situation or IF, the associated behavior or THEN is automatically and unconsciously activated. Research on implementation intentions has shown large effect sizes when compared with other, more willful and conscious goal striving approaches, and in domains as diverse as healthy eating, exercise, anxiety reduction, smoking, studying for exams, and test taking.

A parallel approach, often coupled with implementation intentions due to its added benefit, is mental contrasting (Oettingen, 2012). Here, individuals begin by expressing, in detail, a current wish or goal, including a description of what it will feel like to attain this goal. Next, they identify an obstacle, a problem that might get in the way of achieving the goal, and describe this obstacle in detail. For example, the goal might be to study and learn vocabulary words to do well on an upcoming test, but an obstacle might be the temptation to play with friends. Using this approach, highly costeffective, brief interventions have shown significant gains in goal attainment, in areas involving significant self-control challenges. In particular, results show that mental contrasting, as well as mental contrasting and implementation intentions, can reduce dysregulation in children with $\mathrm{ADHD}$, anxiety, depression, and the depleting effects of using self-control (i.e., minimize the loss of state self-control), while increasing academic performance measures such as grades, attendance, and effort spent studying (reviewed in Hauser, 2018).

The third type of approach to strengthening entails mental transformations, specifically, changing how one thinks about a situation. Early insights into this process came from Mischel's observations of children in the marshmallow task. Some children spontaneously turned the "heat" of the marshmallow temptation into a "cold," unappealing or non-existent trigger by turning away or thinking of the marshmallow as a cloud. Added on to these observations of spontaneous transformations are studies demonstrating ways in which children can be taught, or the context transformed, to help overcome the heat of temptation. For example, recent extensions of the marshmallow task show that using a reliable experimenter (as opposed to unreliable or unfamiliar) extends waiting time for the larger delayed reward (Kidd et al., 2013). This is an important finding for educators, suggesting that they may more readily engage in self-control strategies when provided by a trustworthy, predictable teacher. Other transformative strategies involve self-distancing (White et al., 2015; Grenell et al., 2018) and helping individuals think about the higher level features of a situation (construal), as opposed to the specific, narrow, and local details (Fujita et al., 2006). In self-distancing, individuals effectively run a simulation 
TABLE 2 | Different types of self-control strengthening methods.

\begin{tabular}{|c|c|c|c|}
\hline Strengthening type & Examples & Advantages & Limitations \\
\hline Practicing self-control & $\begin{array}{l}\text { - Engaging in actions that require effort to } \\
\text { sustain (e.g., handgrip practice, } \\
\text { mood regulation) } \\
\text { - Engaging in actions that are } \\
\text { counter-habit (e.g., using non-dominant } \\
\text { hand, avoiding sweets) } \\
\text { - Games (e.g., Simon says; Red } \\
\text { light-Green light) }\end{array}$ & $\begin{array}{l}\text { - Low resource cost } \\
\text { - Low time cost } \\
\text { - Significant effects show up within } 2 \\
\text { weeks } \\
\text { - Easy for a wide range of ages to } \\
\text { understand } \\
\text { - Far generalization } \\
\text { - Often engaging }\end{array}$ & $\begin{array}{l}\text { - No evidence yet of long-term impact } \\
\text { on self-control } \\
\text { - Not always clear that practice } \\
\text { activity specifically targets self- } \\
\text { control as opposed to self-control } \\
\text { plus other processes (e.g., attention, } \\
\text { working memory) } \\
\text { - Unclear if there is a critical period or } \\
\text { lower age boundary where such } \\
\text { practice is ineffective }\end{array}$ \\
\hline Goal attainment & $\begin{array}{l}\text { - Implementation intentions (IF situation } \\
\text { occurs, THEN do this) } \\
\text { - Mental contrasting (Imagine goal/wish, } \\
\text { then consider obstacle to attaining it) } \\
\text { - Mental contrasting + } \\
\text { implementation intentions }\end{array}$ & $\begin{array}{l}\text { - Low resource cost } \\
\text { - Low time cost } \\
\text { - Significant effects emerge within a few } \\
\text { weeks } \\
\text { - Easy for a wide range of ages to } \\
\text { understand } \\
\text { - Underlying cognitive mechanisms } \\
\text { well-understood }\end{array}$ & $\begin{array}{l}\text { - Goal-specific, and thus little evidence } \\
\text { of generalizability } \\
\text { - Limited to children with sufficient } \\
\text { language comprehension and } \\
\text { expression to reframe goals } \\
\text { and obstacles } \\
\text { - Not very engaging } \\
\text { - No evidence yet of long-term, sustained } \\
\text { benefit to self-control }\end{array}$ \\
\hline Mental transformations & $\begin{array}{l}\text { - Transforming "hot" temptations to "cold" } \\
\text { (e.g., not a marshmallow but a cloud) } \\
\text { - Shifting construal level (i.e., focus on } \\
\text { bigger, more global features - the "why" } \\
\text { of action as opposed to "how") }\end{array}$ & $\begin{array}{l}\text { - Low resource cost } \\
\text { - Low time cost } \\
\text { - Can observe effects immediately } \\
\text { - Easy for a wide range of ages to } \\
\text { understand } \\
\text { - Generalizability to other domains of } \\
\text { self-control }\end{array}$ & $\begin{array}{l}\text { - For younger children, may } \\
\text { require coaching by staff to help } \\
\text { change representation } \\
\text { - Not very engaging } \\
\text { - Not clear whether transformations have } \\
\text { long-term, sustained impact } \\
\text { on self-control }\end{array}$ \\
\hline
\end{tabular}

The "Examples" column provides illustrative approaches within the specific type. The "Advantages," and "Limitations" columns refer to the Assessment types as opposed to the specific examples listed for each type; in general, most of the advantages and limitations listed are representative of the examples given. Reviewed in Berkman (2016).

that takes the "I" out of a task that requires self-control (e.g., as in "I can do this") and reframes it in terms of the individual's name (e.g., "Marc can do this!") or someone idolized such as a superhero or great athlete (Superman/Tom Brady could do this!"). Self-distancing has been effective in children ages 4-20 years old. In construal, a child thinking about a math test tomorrow might consider the effort to learn the material, anticipate frustration about the peer who sits in the adjacent chair, anticipate playing with friends instead of studying, and so on-a low level construal. Alternatively, the child may think about getting good grades for the term and the pleasure his parents will express, the opportunities to be involved in after school activities for those with good grades, and so on-high level construal. In studies that help individuals focus on high level construal, results show gains in other aspects of self-control including preferences for delayed as opposed to immediate benefits, greater physical endurance, and reduced attraction to temptations that often derail volitional self-control (Fujita and Carnevale, 2012).

\section{CONCLUSION}

Children may have difficulty accessing the curriculum, not because they lack the intellectual ability, but because they are overwhelmed, distracted, easily frustrated, and impatient. The underlying cause of these challenges is, often, a weak system of self-control. As discussed, however, it is important for teachers to understand self-control as a trait and a state, as well as the difference between volitional and impulsive processes. For children born with poor trait self-control, numerous environmental factors, including poverty and abuse, can compound the problem, both in the long- and short-term, including rapid depletion of the limited resources of state selfcontrol (Caspi et al., 2002; Watts et al., 2018).

Strategies for assessing and strengthening self-control are now readily available, enabling teachers to more precisely and objectively dissect the causes related to interfering behaviors, and then systematically strengthening this system. Ideally, teachers should use a combination of assessment and strengthening strategies to benefit from their unique strengths, target the different processes related to self-control, and overcome some of their specific limitations. Thus, self-report questionnaires together with parent and staff responses to the same questionnaires, can help uncover distortions associated with student misperception or attempts to provide what is wanted as opposed to what is representative. Online games and direct observation can both enhance and help verify results from questionnaires. Similarly, while practicing selfcontrol can help strengthen this system, with evidence for generalization outside of the training context, goal attainment, and mental transformations can provide children with strategies for reframing their challenges, including building habits that bypass the need for willful, conscious, volitional effort. By 
strengthening a child's self-control, teachers will not only have fewer behavior problems to manage in the classroom, and fewer peer disruptions, but will have students who can more readily access the content associated with the curriculum.

\section{REFERENCES}

Baumeister, R. F., Tice, D. M., and Vohs, K. D. (2018). The strength model of selfregulation: conclusions from the second decade of willpower research. Persp. Psych. Sci. 13, 141-145. doi: 10.1177/1745691617716946

Baumeister, R. F., Vohs, K. D., and Tice, D. M. (2007). The strength model of self-control. Curr. Dir. Psych. Sci. 16, 351-355. doi: 10.1111/j.1467-8721.2007.00534.x

Berkman, E. T. (2016). "Self-regulation training," in Handbook of self-regulation, eds K. D. Vos and R. F. Baumeister (New York, NY: The Guilford Press), 440-457.

Berkman, E. T., Graham, A. M., and Fisher, P. A. (2012). Training self-control: a domain-general translational neuroscience approach. Child Dev. Persp. 6, 374-384. doi: 10.1111/j.1750-8606.2012.00248.x

Casey, B. J., Somerville, L. H., Gotlib, I. H., Ayduk, O., Franklin, N. T., Askren, M. K., et al. (2011). Behavioral and neural correlates of delay of gratification 40 years later. Proc. Nat. Acad. Sci. U.S.A. 108, 14998-15003. doi: 10.1073/pnas.1108561108

Caspi, A., McClay, J., Moffitt, T. E., Mill, J., Martin, J., Craig, I. W., et al. (2002). Role of genotype in the cycle of violence in maltreated children. Science 297, 851-854. doi: 10.1126/science.1072290

Cole, P. M., Ram, N., and English, M. S. (2018). Toward a unifying model of self-regulation: a developmental approach. Child Dev. Persp. 79, 555-556. doi: $10.1111 /$ cdep.12316

Danziger, S., Levav, J., and Avnaim-Pesso, L. A. (2011). Extraneous factors in judicial decisions. Proc. Nat. Acad. Sci. U.S.A. 108, 6889-6892. doi: 10.1073/pnas.1018033108

de Ridder, D. T. D., Lensvelt-Mulders, G., Finkenauer, C., Stok, F. M., and Baumeister, R. F. (2011). Taking stock of self-control: a meta-analysis of how trait self-control relates to a wide range of behaviors. Pers. Soc. Psych. Rev. 16, 76-99. doi: $10.1177 / 1088868311418749$

DeBono, A., Shmueli, D., and Muraven, M. (2010). Rude and inappropriate: the role of self-control in following social norms. Pers. Soc. Psych. Bull. 37, 136-146. doi: $10.1177 / 0146167210391478$

Diamond, A. (2013). Executive functions. Ann. Rev. Psych. 64, 135-168. doi: 10.1146/annurev-psych-113011-143750

Duckworth, A., Gendler, T. S., and Gross, J. J. (2014). Self-control in school-age children. Educ. Psych. 49, 199-217. doi: 10.1080/00461520.2014.926225

Duckworth, A. L., Gendler, T. S., and Gross, J. J. (2016). Situational strategies for self-control. Perpect. Psych. Sci. 11, 35-55. doi: 10.1177/1745691615623247

Duckworth, A. L., and Kern, M. L. (2011). A meta-analysis of the convergent validity of self-control measures. J. Res. Pers. 45, 259-268. doi: 10.1016/j.jrp.2011.02.004

Duckworth, A. L., and Steinberg, L. (2015). Unpacking self-control. Child Dev.Perspect. 9, 32-37. doi: 10.1111/cdep.12107

Duckworth, A. L., Taxer, J. L., Eskreis-Winkler, L., Galla, B. M., and Gross, J. J. (2019). Self-control and academic achievement. Ann. Rev. Psych. 70, 373-399. doi: 10.1146/annurev-psych-010418-103230

Duckworth, A. L., and Yeager, D. S. (2015). Measurement matters: assessing personal qualities other than cognitive ability for educational purposes. Ed. Res. 44, 237-251. doi: 10.3102/0013189X15584327

Foulkes, L., and Blakemore, S.-J. (2016). Is there heightened sensitivity to social reward in adolescence? Curr. Opin. Neurob. 40, 81-85. doi: 10.1016/j.conb.2016.06.016

Foulkes, L., and Blakemore, S.-J. (2018). Studying individual differences in human adolescent brain development. Nat. Neuro 21, 315-323. doi: 10.1038/s41593-018-0078-4

Fujita, K., and Carnevale, J. J. (2012). Transcending temptation through abstraction. Curr. Dir. Psych. Sci. 21, 248-252. doi: 10.1177/09637214124 49169

\section{AUTHOR CONTRIBUTIONS}

The author confirms being the sole contributor of this work and has approved it for publication.

Fujita, K., Trope, Y., Liberman, N., and Levin-Sagi, M. (2006). Construal levels and self-control. J. Pers. Soc. Psych. 90, 351-367. doi: 10.1037/0022-3514.90.3.351

Gailliot, M. T. (2012). Breaking the rules: low trait or state selfcontrol increases social norm violations. Psychology 3, 1074-1083. doi: $10.4236 /$ psych.2012.312159

Galla, B. M., and Duckworth, A. L. (2015). More than resisting temptation: beneficial habits mediate the relationship between self-control and positive life outcomes. J. Pers. Soc. Psych. 109, 508-525. doi: 10.1037/pspp00 00026

Gillebaart, M., and de Ridder, D. T. D. (2015). Effortless self-control: a novel perspective on response conflict strategies in trait self-control. Soc. Pers. Psych. Comp. 9, 88-99. doi: 10.1111/spc3.12160

Gollwitzer, P. M. (1999). Implementation intentions: strong effects of simple plans. Am. Psych. 7, 493-503. doi: 10.1037/0003-066X.54.7.493

Grenell, A., Prager, E. O., Schaefer, C., Kross, E., Duckworth, A. L., and Carlson, S. M. (2018). Individual differences in the effectiveness of self-distancing for young children's emotion regulation. Br. J. Dev. Psych. 12, 1070-1017. doi: 10.1111/bjdp.12259

Hauser, M. D. (2018). Mind of a goal achiever: using mental contrasting and implementation intentions to achieve better outcomes in general and special education. Mind Brain Educ.12, 102-109. doi: 10.1111/mbe. 12186

Kauffman, J. M., and Landrum, T. J. (2013). Characteristics of Emotional and Behavioral Disorders of Children and Youth. Upper Saddle River, NJ: Pearson.

Kidd, C., Palmeri, H., and Aslin, R. N. (2013). Rational snacking: young children's decision-making on the marshmallow task is moderated by beliefs about environmental reliability. Cognition 126, 109-114. doi: 10.1016/j.cognition.2012.08.004

Korinek, L., and deFur, S. H. (2016). Supporting student self-regulation to access the general education curriculum. Teach. Exc. Child. 48, 232-242. doi: 10.1177/0040059915626134

Milyavskaya, M., Berkman, E., and De Ridder, D. (2019). The many faces of selfcontrol: tacit assumptions and recommendations to deal with them. Mot. Sci. 5, 79-85. doi: 10.31234/osf.io/h7p58

Mischel, W. (2014). The Marshmallow Test. Boston, MA: Little, Brown and Company.

Moffitt, T. E., Arseneault, L., Belsky, D., Dickson, N., Hancox, R. J., Harrington, H., et al. (2011). A gradient of childhood self-control predicts health, wealth, and public safety. Proc. Nat. Acad. Sci. U.S.A. 108, 2693-2698. doi: $10.1073 /$ pnas. 1010076108

Nigg, J. T. (2016). On the relations among self-regulation, selfcontrol, executive functioning, effortful control, cognitive control, impulsivity, risk-taking, and inhibition for developmental psychopathology. J. Child Psychol. Psych. 58, 361-383. doi: 10.1111/jcpp. 12675

Oettingen, G. (2012). Future thought and behaviour change. Eur. Rev. Soc. Psych. 23, 1-22. doi: 10.1080/10463283.2011. 643698

Oettingen, G., and Gollwitzer, P. M. (2015). "Self-regulation: principles and tools," in Self-Regulation in Adolescence, eds G. Oettingen and P. M. Gollwitzer (Cambridge: Cambridge University Press), 1-28.

Osgood, J. M., and Muraven, M. (2015). Does counting to ten increase or decrease aggression? The role of state self-control (ego-depletion) and consequences. J. App. Soc. Psych. 46, 105-113. doi: 10.1111/jasp.12334

Pandey, A., Hale, D., Das, S., Goddings, A.-L., Blakemore, S.-J., and Viner, R. M. (2018). Effectiveness of universal self-regulation-based interventions in children and adolescents. JAMA Ped. 172, 566-575. doi: 10.1001/jamapediatrics.2018.0232

Steinberg, L., Icenogle, G., Shulman, E. P., Breiner, K., Chein, J., Bacchini, D., et al. (2017). Around the world, adolescence is a time of heightened 
sensation seeking and immature self-regulation. Dev. Sci. 21, e12532-e12545. doi: 10.1111/desc. 12532

Tominey, S. L., and McClelland, M. M. (2011). Red light, purple light: findings from a randomized trial using circle time games to improve behavioral self-regulation in preschool. Early Educ. Dev. 22, 489-519. doi: 10.1080/10409289.2011.574258

Watts, T. W., Duncan, G. J., and Quan, H. (2018). Revisiting the marshmallow test: a conceptual replication investigating links between early delay of gratification and later outcomes. Psych. Sci. 29, 1159-1177. doi: 10.1177/09567976187 61661

Wery, J. J., and Nietfeld, J. L. (2010). Supporting self-regulated learning with exceptional children. Teach. Exc. Child. 42, 70-78. doi: $10.1177 / 004005991004200408$
White, R. E., Kross, E., and Duckworth, A. L. (2015). Spontaneous self-distancing and adaptive self-reflection across adolescence. Child. Dev. 86, 1272-1281. doi: $10.1111 /$ cdev. 12370

Conflict of Interest Statement: MH declares that he is employed by Risk-Eraser, LLC.

Copyright (C) 2019 Hauser. This is an open-access article distributed under the terms of the Creative Commons Attribution License (CC BY). The use, distribution or reproduction in other forums is permitted, provided the original author(s) and the copyright owner(s) are credited and that the original publication in this journal is cited, in accordance with accepted academic practice. No use, distribution or reproduction is permitted which does not comply with these terms. 